\title{
EDUCAÇÃO, SOCIEDADE E DEMOCRACIA: JOHN DEWEY NOS MANUAIS DE HISTÓRIA DA EDUCAÇÃO E/OU PEDAGOGIA (BRASIL, SÉCULO XX)
}

\author{
Geraldo Gonçalves de Lima ${ }^{1}$ \\ Décio Gatti Jr. ${ }^{2}$
}

\section{RESUMO}

Comunicação dos resultados de investigação no âmbito da História da Educação, particularmente na temática da História Disciplinar, cujo foco foram as ideias de John Dewey disseminadas em manuais de História da Educação e/ou Pedagogia, com autores estrangeiros, traduzidos e publicados no Brasil, entre 1939 e 2010, que tiveram ampla circulação em escolas normais e cursos superiores de formação de professores. Partiu-se das ideais de Chervel (1990), Bastos (2006, 2007) e Gatti Jr. (2009). As fontes incluíram bibliografia de referência e doze manuais de História da Educação e/ou Pedagogia. Os resultados apontam para a percepção de quatro ênfases nas abordagens sobre Dewey: herança hegeliana; marcos evolucionistas; relação indivíduo/sociedade (industrial e democrática); emergência da psicologia experimental.

Palavras-chave: História, Educação, Manual, Ensino, Dewey.

\footnotetext{
${ }^{1}$ Instituto Federal de Educação, Ciência e Tecnologia do Triângulo Mineiro (IFTM) - Campus Uberaba, Uberaba/MG, Brasil.

2 Universidade Federal de Uberlândia (UFU), Uberlândia/MG, Brasil.
} 


\section{EDUCACIÓN, SOCIEDAD Y DEMOCRACIA: JOHN DEWEY EN LOS MANUALES DE HISTORIA DE LA EDUCACIÓN Y/O PEDAGOGÍA (BRASIL, SIGLO XX)}

\section{RESUMEN}

Comunicación de los resultados de una investigación en el ámbito de la Historia de la Educación, particularmente en la temática de la Historia Disciplinar, cuyo foco fueron las ideas de John Dewey diseminadas en manuales de Historia de la Educación y/o Pedagogía, con autores extranjeros, traducidos y publicados en Brasil, entre 1939 y 2010, que tuvieron amplia circulación en escuelas normales y cursos superiores de formación de profesores. Se partió de las ideas de Chervel (1990), Bastos (2006, 2007) y Gatti Jr. (2009). Las fuentes incluyeron bibliografía de referencia y doce manuales de Historia de la Educación y/o Pedagogía. Los resultados apuntan hacia la percepción de cuatro énfasis en los abordajes sobre Dewey: herencia hegeliana; marcos evolucionistas; relación individual/sociedad (industrial y democrática); emergencia de la psicología experimental.

Palabras-clave: Historia, Educación, Manual, Enseñanza, Dewey.

\section{EDUCATION, SOCIETY AND DEMOCRACY: JOHN DEWEY IN THE HISTORY OF EDUCATION AND/OR PEDAGOGY MANUALS (BRAZIL, 20TH CENTURY)}

\section{ABSTRACT}

This paper communicates the results of investigation in the area of History of Education, specifically with in the theme of the History of School Subjects, with a focus on the ideas of John Dewey as disseminated in History of Education and/or Pedagogy manuals from foreign authors, translated and published in Brazil from 1939 to 2010. These manuals had wide circulation in teacher training schools and teacher education courses in higher education. This study was based on the ideas of Chervel (1990), Bastos (2006, 2007), and Gatti Jr. (2009). Sources included a reference bibliography and twelve History of Education and/or Pedagogy manuals. Results indicate perception of four emphases in approaches to Dewey: Hegelian legacy, evolutionist features, individual / society relationship (industrial and democratic) and the emergence of experimental psychology.

Keywords: History, Education, Manual, Teaching, Dewey.

\section{ÉDUCATION, SOCIÉTÉ ET DÉMOCRATIE: JOHN DEWEY DANS LES MANUELS D'HISTOIRE DE L'ÉDUCATION ET/OU PÉDAGOGIE (BRÉSIL, SIÈCLE $\mathbf{X X )}$}

\section{RÉSUMÉ}

La communication des résultats de recherche dans l'Histoire de l'Éducation, en particulier dans le domaine de l'Histoire Disciplinaire, s'est concentrée sur les idées de John Dewey diffusées dans des manuels d'Histoire de l'Éducation et/ou Pédagogie avec des auteurs étrangers traduits 
et publiés au Brésil, entre 1939 et 2010, qui avait la large difusión dans les écoles normales et des cours de formation des enseignants. Il était basé sur les idéaux de Chervel (1990), Bastos (2006, 2007) et Gatti Jr. (2009). Les sources comprennent une bibliographie de référence et douze manuels d'Histoire de l'Éducation et/ou Pédagogie. Les résultats indiquent la perception de quatre priorités dans les approches de Dewey: héritage hégélien; cadres évolutifs; relation entre l'individu et la société (industrielle et démocratique); émergence de la psychologie expérimentale.

Mots-clés: Histoire, Éducation, Manuel, Enseignement, Dewey. 


\section{INTRODUÇÃO}

Neste artigo, busca-se compreender as concepções de educação, sociedade e democracia na obra de John Dewey (1859-1952), bem como as repercussões de tais ideias na formação de professores brasileiros, por meio da análise do conteúdo disposto em importantes manuais disciplinares de História da Educação e/ou Pedagogia, com autores estrangeiros, traduzidos para o português e publicados no Brasil entre 1939 e 2010.

Deste modo, por meio de pesquisa bibliográfica com tratamento analítico e interpretativo de modo qualitativo, são abordados dois temas principais: as ideias centrais do pensamento filosófico de John Dewey (18591952) e a forma como elas foram apresentadas em diferentes manuais de História da Educação e/ou Pedagogia destinados à formação de professores no Brasil, por meio do exame dos conteúdos de doze manuais com autores estrangeiros que foram traduzidos e publicados no Brasil entre 1939 e 2010, os quais influenciaram o ensino da disciplina em diversas regiões do país.

\section{A ABORDAGEM DOS MANUAIS DISCIPLINARES NA HISTÓRIA DA EDUCAÇÃO E/OU PEDAGOGIA.}

A partir das décadas de 1970 e 1980, no contexto da renovação teóricometodológica da pesquisa em História da Educação, houve ampliação e renovação dos objetos de investigação, assim como o desenvolvimento de novas perspectivas, de novas abordagens, de novos conceitos e de novas metodologias. No Brasil, a História da Educação, em suas origens, tinha se dedicado principalmente à História das Instituições Escolares e à História das Ideias Pedagógicas, sendo que, na segunda metade da década de 1990, emergiu a História das Disciplinas Escolares.

No âmbito da História das Disciplinas Escolares destinadas à formação 
de professores, por exemplo a História da Educação e/ou Pedagogia, é importante abordar e investigar as finalidades prescritas (religiosas, sóciopolíticas, psicológicas, culturais, comportamentais etc.), assim como a contraposição em relação às práticas efetivamente presentes na realidade escolar, a partir da perspectiva de Chervel (1990).

Dentre os campos de investigação da História das Disciplinas Escolares, ganham destaque a pesquisa, o tratamento e a análise de manuais escolares, como aqueles utilizados em Escolas Normais e/ou cursos superiores, localizados no âmbito do currículo prescrito, e que são utilizados como material pedagógico central no desenvolvimento das atividades de ensino, incluindo a explanação de conteúdos programáticos e a aplicação de testes avaliativos.

Efetivamente, os textos e impressos destinados à instrução ensejam essas abordagens. Eles são, com efeito, em maior ou menor grau, desde o século XIX, objetos de controle do Estado e, desde a Idade Moderna, instrumentos por excelência, de proselitismo religioso. Eles, de fato, reproduzem e condicionam um modo de organização da cultura escolar, concepções pedagógicas, maneiras de escolarizar saberes. Eles são, portanto, realmente, objetos por meio dos quais se pode buscar construir a história dos modos de conceber, pelo Estado, a formação ideológica da criança, bem como dos processos pelos quais a escola constrói sua cultura, seus saberes, suas práticas (GALVÃO; BATISTA, 2003, p. 166).

Nessa direção, os manuais disciplinares de História da Educação e/ou Pedagogia suportam e fazem circular ideias sociais e políticas em seus conteúdos, que têm como destinatários principais o público que frequenta, os cursos de formação de professores, seja na Escola Normal ou nos diferentes cursos de formação superior, sendo portadores de conteúdos e de sugestões do modo de os ensinar, o que permite perceber as diferenças de abordagem e as transformações pelas quais a disciplina passou ao longo do tempo, pois que 
currículos escolares; compreendido os processos que conferiram identidade às disciplinas ou percebido as diferentes identidades que elas assumiram em diversificados lugares institucionais nas diferentes temporalidades; apreendido a diversidade de perfis programáticos que as disciplinas possam ter assumido ao longo do tempo; percebido o perfil dos docentes que se têm dedicado ao ensino das disciplinas escolares; desvendando as marcas histórico-educativas que perpassam os materiais pedagógicos fundamentais no trabalho escolar, com centralidade nos manuais pedagógicos/livros didáticos (GATTI JR., 2009, p. 102).

Por meio da análise e da interpretação de manuais disciplinares de História da Educação e/ou Pedagogia, é possível, por exemplo, buscar as ideias em circulação acerca de diversos intelectuais proeminentes nos meios acadêmicos e movimentos filosóficos que tiveram repercussão nos lugares de formação docente e que atuaram em escolas de ensino primário e/ou de educação básica, pois os

manuais revelam um ideal pedagógico que contribuiu para o reforço ao seu público (normalistas em formação, alunos de licenciaturas, além dos professores), no qual à docência é concebida como sacerdócio, mas especialmente com uma concepção de educação de forte conteúdo doutrinário, seja do ponto de vista do humanismo tradicional católico, seja do humanismo moderno disseminado pelo escolanovismo - herdeiro do hegelianismo, do evolucionismo, do positivismo e do cientificismo. [...] Em relação à concepção de história da educação, é fundamental destacar a prevalência de uma visão linear, cronográfica e, via de regra, factual em todas as obras, as quais privilegiam uma visão universal da educação, porém de caráter eurocêntrico (ARAÚJO; RIBEIRO; SOUZA, 2011, p. 135).

Como desdobramento da escolha do foco de trabalho de investigação e interpretação no âmbito de uma História Disciplinar mais geral, a efetivação da presente pesquisa ocorreu mediante a utilização de materiais históricos variados que incluíram alguns dos manuais de História da Educação e/ou Pedagogia em circulação nos cursos de formação de professores do Brasil (século XX), mas, também, obras de destaque de John Dewey. 


\section{EDUCAÇÃO, POLÍTICA E DEMOCRACIA EM JOHN DEWEY.}

A investigação buscou compreender o pensamento de John Dewey, sobretudo em torno de ideias como Educação, Política e Democracia, assim como sua repercussão em movimentos pedagógicos, sobretudo, o escolanovismo.

Vale reforçar que a obra de John Dewey teve sua consolidação presenciada na primeira metade do século XX. Este momento histórico, por um lado, testemunhou os embates entre a gênese de modelos políticos totalitários como o movimento nazista (Alemanha) e fascista (Itália); o regime comunista da União Soviética (URSS); assim como as democracias liberais da Europa ocidental, Estados Unidos etc.

\footnotetext{
Uma democracia americana somente pode servir ao mundo se demonstrar, na conduta de sua própria vida, a eficácia dos métodos pluralísticos, parciais e experimentais em assegurar e manter uma libertação sempre crescente das potencialidades da natureza humana, a serviço de uma libertação que é cooperativa e uma cooperação que é voluntária. (DEWEY, 1970, p. 261).
}

John Dewey, dentre outras temáticas de abordagem, vislumbrou na Educação, uma estratégia de divulgação dos princípios políticas da democracia, como forma de consolidar os direitos políticos e sociais dos cidadãos.

Deste modo, considerou-se fundamentais a abordagem e o tratamento de algumas das obras de Dewey, conforme apresentadas no Quadro 1, como esforço de entendimento de suas principais categorias teóricas, voltadas especificamente para a compreensão de ideias como Educação, Sociedade e Democracia.

Quadro 1 - Obras de John Dewey analisadas. 


\begin{tabular}{|c|c|c|c|}
\hline $\begin{array}{c}\text { ANO DA EDIÇÃ̃ } \\
\text { ANALISADA }\end{array}$ & TÍTULO & TRADUÇÃo & EDITORA \\
\hline 1936 & $\begin{array}{c}\text { Democracia e } \\
\text { Educação }\end{array}$ & $\begin{array}{c}\text { Godofredo Rangel / } \\
\text { Anísio Teixeira }\end{array}$ & $\begin{array}{c}\text { Companhia } \\
\text { Editora Nacional }\end{array}$ \\
\hline 1958 & $\begin{array}{c}\text { A Filosofia em } \\
\text { Reconstrução }\end{array}$ & $\begin{array}{c}\text { Eugênio Marcondes } \\
\text { Rocha }\end{array}$ & $\begin{array}{c}\text { Companhia } \\
\text { Editora Nacional }\end{array}$ \\
\hline 1970 & $\begin{array}{c}\text { Liberalismo, } \\
\text { liberdade e cultura }\end{array}$ & Anísio Teixeira & $\begin{array}{c}\text { Companhia } \\
\text { Editora Nacional }\end{array}$ \\
\hline 1979 & $\begin{array}{c}\text { Experiência e } \\
\text { Educação }\end{array}$ & Anísio Teixeira & Editora Nacional \\
\hline
\end{tabular}

Fonte: Elaborado pelos autores, a partir de acervo particular.

Desta maneira, pretende-se realizar, neste momento do artigo, uma apresentação panorâmica do pensamento de John Dewey, com destaque para a exposição de sua visão filosófica em torno de ideias como Educação, vista como um processo complexo, dinâmico e de identificação dos aspectos vitais humanos.

Se buscarmos formular a filosofia da educação implícita nas práticas da educação mais nova, podemos, creio, descobrir certos princípios comuns por entre a variedade de escolas progressivas ora existentes. $\grave{A}$ imposição de cima para baixo, opõe-se a expressão e cultivo da individualidade; à disciplina externa, opõe-se a atividade livre; a aprender por livros e professores, aprender por experiência; à aquisição por exercício e treino de habilidades e técnicas isoladas, a sua aquisição como meios para atingir fins que respondem a apelos diretos e vitais do aluno; à preparação para um futuro mais ou menos remoto opõe-se aproveitar-se ao máximo das oportunidades do presente; a fins e conhecimentos estáticos opõe-se a tomada de contacto com um mundo em mudança. (DEWEY, 1979, p. 6-7).

Além do mais, demonstrar também que a Educação se tornou condição para o desenvolvimento das habilidades políticas, entendidas como essenciais no exercício do poder de convivência democrática, colocada em risco, sobretudo 
durante o auge da produção bibliográfica de John Dewey, ao longo da primeira metade do século XX.

Os dois elementos de nosso critério se orientam para a democracia. $\mathrm{O}$ primeiro significa não só mais numerosos e variados pontos de participação do interesse comum, como também maior confiança no reconhecimento de serem, os interesses recíprocos, fatores da regulação e direção social. E o segundo não só significa uma cooperação mais livre entre os grupos sociais (antes isolados tanto quanto voluntariamente o podiam ser) como também a mudança dos hábitos sociais - sua contínua readaptação para ajustar-se às novas situações criadas pelos vários intercâmbios. (DEWEY, 1936, p. 117-8).

A escolha para o exame do pensamento filosófico de Dewey está relacionada à importância de sua obra e à repercussão de suas ideias no Brasil, como também a influência sobre o Movimento Escolanovista, pois "a escola tem igualmente a função de coordenar, na vida mental de cada indivíduo, as diversas influências dos vários meios sociais em que ele vive" (DEWEY, 1936, p. 44).

No Brasil, destacadamente, por meio da atuação, da militância e das obras de seu representante Anísio Teixeira (1900-1971), houve a expansão dos ideais da Escola Nova, tendo em vista a renovação do ensino, proposta por Dewey, por meio da busca de uma reorientação das práticas pedagógicas, com base na visão de centralidade em torno do educando.

Na formação pedagógica de Anísio Teixeira, foram decisivas as duas viagens que fez aos Estados Unidos. Da primeira, em 1927, resultou o livro Aspectos americanos da educação, publicado em 1928, no qual relata os resultados de sua viagem, apresentando comentários sobre estabelecimentos de ensino, órgãos de administração, edifícios, métodos práticos de ensino, currículo flexível e variado, vida estudantil, além de uma primeira sistematização da concepção de Dewey. Com certeza foi essa experiência que o motivou a retornar aos Estados Unidos em 1929 para realizar o mestrado na Universidade de Columbia, ocasião em que fez estudos com Dewey. (SAVIANI, 2007, p. 227). 
Dewey ganhou notoriedade no campo filosófico e pedagógico, tendo em vista a repercussão de suas ideias acerca de temas como o pensamento reflexivo, a relação entre a democracia e a educação, a epistemologia, o papel da experiência e da teoria na formação humana etc., pois "pensamento, desejo e propósito resultam de uma interação entre a pessoa e as condições ambientes, num permanente dar e receber" (DEWEY, 1970, p. 65). Sua obra teórica e sua atuação como educador exerceram influência em diversas partes do mundo, inclusive no Brasil.

John Dewey foi o filósofo norte-americano mais importante da primeira metade do século XX. Sua carreira cobre a vida de três gerações e sua voz pôde ser ouvida no meio das controvérsias culturais dos Estados Unidos (e do estrangeiro) desde a década de 1890, até sua morte em 1952, quando completara 92 anos de idade. Ao longo de sua carreira, Dewey desenvolveu uma filosofia que advogava a unidade entre teoria e prática, unidade de que dava exemplo em sua própria ação como intelectual e militante político. O pensamento dele baseavase na convicção moral de que "democracia é liberdade" -, ao que dedicou toda sua vida, elaborando uma argumentação filosófica para fundamentar esta convicção [...]. O compromisso de Dewey com a democracia e com a integração entre teoria e prática foi, sobretudo, evidente em sua carreira de reformador da educação. [...] As opiniões filosóficas de Dewey provavelmente chegaram a um maior número de leitores por meio das obras destinadas aos educadores [...]. Não é por mera casualidade que ele observava que, como ele, muitos grandes filósofos interessaram-se pelos problemas da educação, já que existe "estreita e essencial relação entre a necessidade de filosofar e a necessidade de educar". Se filosofia fosse sabedoria - a visão de uma "maneira melhor de viver" -, a educação orientada conscientemente constituiria a práxis do filósofo. (WESTBROOK, 2010, p. 11-2).

Dentre estes movimentos atuantes na realidade brasileira, podemos citar o escolanovismo, que defendia a superação das mazelas tradicionalistas do ensino e a propagação de valores tais como a individualidade, a relação entre a teoria e a prática, a democracia e a educação, a liberdade de ensino, a escola pública (laica e universal). "Em suma, o ponto que desejo acentuar é que a rejeição da filosofia e da prática da escola tradicional levanta, para os que acreditam em um novo tipo de educação, um novo tipo de difícil problema 
educacional." (DEWEY, 1979, p. 13). Em outras palavras, o movimento da Escola Nova no Brasil se contrapõe às tendências até então consideradas tradicionais, destacadamente a de matriz católica.

Com este objectivo, sustenta que a escola deve consistir numa sociedade em miniatura, organizando-se como uma comunidade embrionária. [...] A organização da aprendizagem em torno de actividades, como preconizado pela educação progressiva, e da resolução de problemas suscitada pelas mesmas, conduz a uma assinalável alteração no ambiente escolar, que se traduz num incentivo natural à assistência mútua, como forma de cooperação e associação, ao contrário do que se passava no registro da educação tradicional, marcada por um elevado grau de individualismo e de competição. [...] Assiste-se, assim, a uma renovação da escola, que passa a estar organizada numa verdadeira base social, proporcionando aos estudantes vivências democráticas, com consequências na manutenção e renovação do sistema social mais lato. Um aspecto fundamental desta concepção é a ênfase colocado (sic) na educação escolar como libertação das possibilidades do espírito humano e no fortalecimento da organização social, em detrimento de meros objectivos utilitários ou economicistas (BRANCO, 2011, p. 20).

Com este intuito, John Dewey vislumbrou na experiência educacional escolar a condição sine qua non para o desenvolvimento cognitivo, ético e estético dos educandos como forma para a expansão da experiência política, de modo a aperfeiçoar ideais democráticos na sociedade contemporânea. Neste sentido,

Sem essa educação formal é impossível a transmissão de todos os recursos e conquistas de uma sociedade complexa. Ela abre, além disso, caminho a uma espécie de experiência que não seria acessível aos mais novos, se estes tivessem de aprender associando-se livremente com outras pessoas, desde que livros e símbolos do conhecimento têm que ser aprendidos. (DEWEY, 1936, p. 27)

É importante mencionar que Dewey indispôs-se com a pura especulação teórica e buscou novas formas de relacionar a Filosofia com as questões práticas da vida cotidiana. Empenhou-se na fundação de uma escola elementar, na 
Universidade de Chicago: "Escola-Laboratório" (MARICONDA, 1980, p. VI).

“A escola é parte da obra de educação, mas, em um sentido amplo, educação inclui todas as influências que contribuem para formar as atitudes e disposições (de desejo tanto quanto de crença) que constituem os hábitos dominantes da mente e do caráter” (DEWEY, 1970, p. 62). É importante salientar que a matriz filosófica do pensamento deweyano é o Pragmatismo, que segundo consta em Abbagnano (2007, p. 784), trata-se de um termo que

foi introduzido na filosofia em 1898 , por um relatório de W. James a Califórnia Union, em que ele se referia à doutrina exposta por Peirce num ensaio do ano 1878, intitulado 'Como tornar claras as nossas idéias'. Alguns anos mais tarde, Peirce declarava ter inventando o nome Pragmatismo para a teoria segundo a qual '(sic) uma concepção, ou seja, o significado racional de uma palavra ou de outra expressão, consiste exclusivamente em seu alcance concebível sobre a conduta da vida' (sic); dizia também que preferia esse nome a praticismo ou praticalismo porque, para quem conhece o sentido atribuído a "prático" pela filosofia kantiana, estes últimos termos fazem referência ao mundo moral, onde não há lugar para a experimentação, enquanto a doutrina proposta é justamente uma doutrina experimentalista. Todavia, no mesmo artigo, Peirce declarava que em face da extensão do significado de que o Pragmatismo fora alvo por obra da W. James e de F. C. Schiller, preferia o termo pragmaticismo, para indicar sua própria concepção, estritamente metodológica, do Pragmatismo [...]. Dessa maneira, Peirce acabava distinguindo duas versões fundamentais de Pragmatismo, que pode ser assim caracterizadas: $\mathrm{I}^{\mathrm{a}}$ um Pragmatismo metodológico, que é substancialmente uma teoria do significado; $2^{\mathrm{a}}$ um Pragmatismo metafísico, que é uma teoria da verdade e da realidade.

Contudo, o pensamento de Dewey pode ser melhor caracterizado como um "instrumentalismo", para diferenciá-lo dos pragmatismos de Charles Peirce (1839-1914) e de William James (1842-1910), dos quais partira. "A solução estará na descoberta de como a familiarização com o passado poderá traduzir-se em poderosa instrumentalidade para melhor lidar efetivamente com o futuro" (DEWEY, 1979, p. 11). Logo, 
A filosofia de Dewey foi definida como "naturalismo": é filosofia que se move no leito do pragmatismo e se situa no quadro da tradição empirista. Entretanto, Dewey optou por chamar a sua filosofia de instrumentalismo, que, em primeiro lugar, se diferencia do empirismo clássico quando ao conceito de experiência. A experiência dos empiristas clássicos é simplificada, ordenada e purificada de todos os elementos de desordem e erro, reduzida a estados de consciência claros e distintos, ao passo que Dewey, em Experiência e natureza (1925), sustenta que "a experiência não é consciência, e sim história" (REALE; ANTISERI, 1991, p. 503).

Com isso, para Dewey, o conhecimento pode ser considerado uma ação direcionada e componente funcional da experiência, "[...] portanto, a nova filosofia de educação comprometida com alguma espécie de filosofia empírica e experimental” (DEWEY, 1979, p. 13). Além do mais, o pensamento não tem um fim em si mesmo, pois constitui parte da própria vida, sendo, portanto, mobilização voltada para a atividade do indivíduo, referência para a ação (MARICONDA, 1980). Para Cunha (1998, p. 32):

A concepção de conhecimento aqui exposta é justamente o que atribui à filosofia de John Dewey um caráter distinto das demais correntes do pensamento filosófico. A atividade reflexiva não se submete a qualquer instância que não seja definida pela experiência de organizar o mundo concreto de acordo com as necessidades da vida humana e, completamente, pela capacidade genuinamente humana de ajustamento às condições oferecidas pelo meio. Trata-se de uma filosofia que desce das alturas metafísicas em que usualmente se coloca o pensar e se embrenha nas coisas terrenas que dizem respeito diretamente à vida das pessoas.

Esta identidade entre pensamento e vida possibilita a ideia de que a racionalidade da natureza não constitui meramente um postulado teórico, mas uma potencialidade humana em interferir ativamente nos diferentes fenômenos. Logo, o Instrumentalismo considera a inteligência não como uma realidade distinta, alheia, mas componente e efeito da própria natureza. 
lazeres, também se faz o mesmo com a teoria e a prática, a inteligência e a ação, o saber e o fazer. Estes últimos antagonismos promanam, indubitavelmente, das mesmas condições sociais que geram a primeira oposição; mas determinados problemas de educação relacionados com eles tornam desejável examinar claramente as conexões e a pretensa separação entre o saber e o fazer. (DEWEY, 1936, p. 325)

Em outras palavras, por meio do Instrumentalismo, houve a possibilidade do restabelecimento da unidade espiritual, superando a visão tradicional de Pedagogia (MARICONDA, 1980). Nessa direção, para Reale e Antiseri (1991, p. 509):

\begin{abstract}
A inteligência, pois, é constitutivamente operativa. A razão não é meramente contemplativa: é força ativa chamada a transformar o mundo em conformidade com objetivos humanos. Claro, a contemplação é ela própria uma experiência, mas, para Dewey, ela constitui a parte final, na qual o homem desfruta do espetáculo dos seus processos. O processo cognoscitivo não é contemplação, mas sim participação nas vicissitudes do mundo que deve ser mudado e reorganizado sem descanso.
\end{abstract}

Ao desenvolver sua Filosofia, John Dewey trata não apenas das questões relacionadas ao conhecimento, sobretudo científico, mas também se volta para os fundamentos da Pedagogia, pois a educação configura processo social e individual crítico para o aperfeiçoamento do convívio, ajustada para a solução dos problemas e das questões cotidianas nas diversas sociedades. Para o autor, "chegamos assim a uma definição técnica da educação: uma reconstrução ou reorganização da experiência, que esclarece e aumenta o sentido desta e também a nossa aptidão para dirigirmos o curso das experiências subsequentes” (DEWEY, 1936, p. 107). Logo,

Uma filosofia ajustada ao presente deve tratar daqueles problemas que resultam de mudanças que se processam num setor humanogeográfico em escala cada vez mais ampla e com poder de rapidez e de penetração cada vez mais intenso; eis aí uma indicação bem marcante da necessidade que se faz sentir de uma espécie da reconstrução 
diversa, em todos os sentidos, daquela que está agora em evidência (DEWEY, 1958, p. 3).

A noção de experiência em Dewey consiste em uma categoria fundamental para a compreensão do pensamento e da obra do autor, relacionada à vivência do cotidiano, em comum com os demais indivíduos. Por outro lado, nem toda experiência é considerada educativa, sendo fundamentais algumas determinadas condições. Em outras palavras,

[...] a experiência, para ser educativa, deve conduzir a um mundo expansivo de matérias de estudo, constituídas por fatos ou informações, e de ideias. Esta condição somente é satisfeita quando o educador considera o ensino e a aprendizagem como um processo contínuo de reconstrução da experiência (Dewey, 1958, p. 118).

Ademais, por excelência, as dimensões filosóficas voltadas para a reflexão e o pensamento crítico estão intimamente relacionadas com outras questões que perpassam pela Política e pela Educação ${ }^{3}$. Não há possibilidade de um processo educacional autêntico ocorrer desvinculado da realidade política e da vida em sociedade. Neste sentido,

A única liberdade de importância duradoura é a liberdade de inteligência, isto é, liberdade de observação e de julgamento com respeito a propósitos intrinsecamente válidos e significativos. O erro mais comum que se faz em relação à liberdade é o de identificá-la com liberdade de movimento, ou com o lado físico e exterior da atividade. Este lado exterior e físico da atividade não pode ser separado do seu lado interno, a liberdade de pensar, desejar e decidir (DEWEY, 1979, p. 59).

3 Para Popkewitz (2015), na América do Norte e na Europa Setentrional, o processo de escolarização retrata temas de salvação, que seriam expressões iluministas, tendo em vista o entendimento da cidadania cosmopolita e do progresso da razão, por meio da Ciência. Contudo, as iniciativas de emancipação nunca foram envolvidas com as noções de liberdade e de inclusão, pois um sistema de comparação foi estabelecido. Em uma visão otimista, esperava-se que a criança tornar-se-ia um futuro cidadão cosmopolita, mas também incorporava os temores diante do futuro, em uma postura pessimista. Essa dubiedade estava presente nas reformas da educação progressiva nos Estados Unidos, assim como nos estudos investigativos sobre a criança e no pragmatismo na virada do século XX. 
No pensamento e no engajamento social de Dewey, em tempos de avanço das doutrinas políticas totalitaristas (fascismo, nazismo, comunismo etc.) em diversos países do mundo europeu, não há sentido também em especularmos ou engajarmos em termos de Política, sem considerá-la como condição sine qua non para a vida democrática, enquanto modelo adequado para o desenvolvimento da vida em comunidade. Logo,

\begin{abstract}
A situação presente da democracia pode ser assim exposta: a democracia pressupõe a crença de que as instituições políticas e a lei possam ser tais que consubstanciem de modo fundamental a natureza humana. Devem permitir e promover uma atuação mais livre da natureza humana do que quaisquer outras instituições nãodemocráticas. Ao mesmo tempo, a teria, legal e moral, sobre a natureza humana, que se elaborou para expor e justificar essa dependência e fundamentação em sua constituição, revelou-se inadequada (DEWEY, 1970, p. 211).
\end{abstract}

Conclui-se que a compreensão e a abordagem das principais concepções filosóficas e pedagógicas de Dewey podem colaborar para o entendimento do processo histórico de surgimento de movimentos educacionais de tendências diversas, os quais tiveram presença marcante no século XX.

\title{
3. JOHN DEWEY NOS MANUAIS DISCIPLINARES DE HISTÓRIA DA EDUCAÇÃO E/OU PEDAGOGIA.
}

Baseados na apresentação panorâmica das ideias filosóficas do pensador John Dewey acerca das categorias teóricas de Educação, Sociedade e Democracia, como uma das possíveis abordagens especulativas dos desdobramentos no campo escolar, de formação de professores, nos dedicaremos a partir de agora ao cotejamento entre estas ideias presentes na obra deweyana e a sua respectiva abordagem nos manuais de História da Educação e/ou Pedagogia. 
Os referidos manuais (ver Quadro 2, abaixo) de História da Educação e/ou Pedagogia são de autoria estrangeira (europeus e americanos), traduzidos para a Língua Portuguesa, e os quais tiveram ou têm intensa circulação no Brasil em cursos de formação de professores, seja em escolas normais ou em cursos de graduação / pós-graduação, a partir de levantamentos anteriores, que demonstraram a presença de tais manuais em planos de cursos e/ou bibliotecas das instituições escolares investigadas.

Quadro 2. Manuais de História da Educação e/ou Pedagogia com autores estrangeiros, traduzidos para a Língua Portuguesa e em circulação no Brasil (1939-2010).

\begin{tabular}{|c|c|c|c|c|}
\hline $\begin{array}{l}\text { 1 }^{\text {a }} \text {. ED. } \\
\text { BRASIL }\end{array}$ & $\begin{array}{l}1^{\text {a }} \text {. ED. } \\
\text { ORIGINAL }\end{array}$ & AUTOR & TÍTULO & EDITORA \\
\hline 1939 & 1907 & Monroe & História da Educação & $\begin{array}{c}\text { Companhia } \\
\text { Editora } \\
\text { Nacional }\end{array}$ \\
\hline 1951 & 1925 & Riboulet & História da Pedagogia & $\begin{array}{c}\text { Editôra } \\
\text { Coleção F.T.D. }\end{array}$ \\
\hline 1954 & 1948 & Gal & História da Educação & Martins Fontes \\
\hline 1955 & 1951 & Luzuriaga & $\begin{array}{c}\text { História da Educação e da } \\
\text { Pedagogia }\end{array}$ & $\begin{array}{c}\text { Companhia } \\
\text { Editora } \\
\text { Nacional }\end{array}$ \\
\hline 1957 & 1949 & Hubert & História da Pedagogia & $\begin{array}{c}\text { Companhia } \\
\text { Editora } \\
\text { Nacional }\end{array}$ \\
\hline 1962 & 1952 & Eby & $\begin{array}{l}\text { História da Educação } \\
\text { Moderna: teoria, organização e } \\
\text { práticas educacionais (séc. } \\
\text { XVI - séc. XX) }\end{array}$ & Editora Globo \\
\hline 1963 & 1937 & Ponce & Educação e luta de classes & Cortez Editora \\
\hline 1970 & 1944 & Larroyo & História Geral da Pedagogia & $\begin{array}{c}\text { Editora Mestre } \\
\text { Jou }\end{array}$ \\
\hline
\end{tabular}




\begin{tabular}{|c|c|c|c|c|}
\hline 1974 & 1971 & $\begin{array}{c}\text { Debesse \& } \\
\text { Mialaret }\end{array}$ & $\begin{array}{c}\text { Tratado das Ciências } \\
\text { Pedagógicas 2: história da } \\
\text { pedagogia }\end{array}$ & $\begin{array}{c}\text { Companhia } \\
\text { Editora } \\
\text { Nacional }\end{array}$ \\
\hline 1989 & 1983 & Manacorda & $\begin{array}{c}\text { História da Educação: da } \\
\text { Antiguidade aos nossos dias }\end{array}$ & Cortez Editora \\
\hline 1999 & 1995 & Cambi & História da Pedagogia & Editora \\
\hline 2010 & 2005 & $\begin{array}{c}\text { Gauthier \& } \\
\text { Tardif }\end{array}$ & $\begin{array}{c}\text { A pedagogia. Teorias e práticas } \\
\text { da Antiguidade aos nossos dias }\end{array}$ & Editora Vozes \\
\hline
\end{tabular}

Fonte: Elaborado pelos autores, a partir de informações contidas em: Bastos (2006, 2007); Gatti Jr. (2007, 2014); Nunes (1996); Saviani (2008).

A opção pela realização de pesquisa que envolve o exame das representações formuladas por autores de manuais pedagógicos de História da Educação e/ou Pedagogia em circulação pelo Brasil no século XX, sobre as ideias de Dewey, justifica-se por sua importância na consumação da História da Filosofia Contemporânea, assim como a influência sobre a Educação Nova nos Estados Unidos, no mundo e no escolanovismo brasileiro, sobretudo, neste último, por meio da atuação de Anísio Teixeira.

No Quadro 3, estão listadas as informações sobre o conteúdo dos referidos manuais escolares de História da Educação e/ou Pedagogia, buscando sobretudo os trechos nos quais os autores mencionam Dewey. 
Quadro 3 - John Dewey nos manuais de História da Educação e/ou Pedagogia.

\begin{tabular}{|c|c|c|c|c|}
\hline $\begin{array}{l}\text { AUTOR 1a . ED } \\
\text { BRASIL / } \\
\text { EDIÇÃO } \\
\text { UTILIZADA }\end{array}$ & $\begin{array}{l}\text { PÁGINAS } \\
\text { SOBRE } \\
\text { DEWEY }\end{array}$ & $\begin{array}{l}\text { PÁGINAS } \\
\text { DA OBRA }\end{array}$ & $\%$ & $\begin{array}{l}\text { DESCRIÇÃO DO CONTEÚDO } \\
\text { SOBRE DEWEY }\end{array}$ \\
\hline $\begin{array}{c}\text { Monroe } \\
(1939 / 1978)\end{array}$ & $1(371)$ & 387 & 0,25 & $\begin{array}{l}\text { Conclusões: a tendência eclética } \\
\text { atual. Fusão das tendências } \\
\text { psicológica, científica e sociológica. } \\
\text { Tendências correntes em educação. A } \\
\text { conciliação entre o interesse e o } \\
\text { esforço. O sentido da educação. O } \\
\text { currículo. O método. O problema } \\
\text { permanente. }\end{array}$ \\
\hline $\begin{array}{l}\text { Riboulet } \\
(1951 / 1951)\end{array}$ & o & 204 & 0,00 & $\begin{array}{l}\text { Pedagogia protestante: [...] William } \\
\text { James (1842-1910) (p. 20-25) }\end{array}$ \\
\hline $\begin{array}{c}\text { Gal } \\
(1954 / 1989)\end{array}$ & $1(111)$ & 115 & 0,86 & $\begin{array}{l}\text { Conclusão: Cita John Dewey como } \\
\text { um dos representantes da "Educação } \\
\text { Nova" (p. 111) }\end{array}$ \\
\hline $\begin{array}{l}\text { Luzuriaga } \\
(1955 / 1955)\end{array}$ & $2(256-7)$ & 298 & 0,67 & $\begin{array}{l}\text { A Educação Nova. } 6 \text {. As escolas novas } \\
\text { norte-americanas. }\end{array}$ \\
\hline $\begin{array}{c}\text { Hubert } \\
(1957 / 1967)\end{array}$ & $9(312-20)$ & 394 & 2,28 & $\begin{array}{l}\text { Algumas tendências da pedagogia } \\
\text { contemporânea. John Dewey. }\end{array}$ \\
\hline $\begin{array}{c}\text { Eby } \\
(1962 / 1962)\end{array}$ & $15(531-45)$ & 633 & 2,36 & O Instrumentalismo de John Dewey. \\
\hline $\begin{array}{c}\text { Ponce } \\
(1963 / 1998)\end{array}$ & o & 196 & 0,00 & - \\
\hline $\begin{array}{c}\text { Larroyo } \\
(1970 / 1970)\end{array}$ & $3(724-6)$ & 450 & 0,66 & $\begin{array}{l}\text { A Pedagogia Contemporânea. } \\
\text { Pedagogia da Ação. Os grandes } \\
\text { teóricos da Pedagogia Ativista. John } \\
\text { Dewey e o "ensino pela ação". }\end{array}$ \\
\hline $\begin{array}{c}\text { Debesse \& } \\
\text { Mialaret } \\
\text { (1974-7/1977) }\end{array}$ & $\begin{array}{l}3(201 ; 476 ; \\
520)\end{array}$ & 559 & 0,05 & Referências esporádicas \\
\hline Manacorda & $8(317-23$ & 382 & 2,09 & $\begin{array}{l}\text { O nosso século em direção ao ano } \\
\text { 2000. A primeira metade do século. }\end{array}$ \\
\hline
\end{tabular}




\begin{tabular}{|c|c|c|c|c|}
\hline (1989/2004) & 336) & & & $\begin{array}{l}\text { Os problemas da instrução nas } \\
\text { democracias burguesas. A segunda } \\
\text { metade do século. Novas tendencias } \\
\text { dos marxistas e dos católicos. }\end{array}$ \\
\hline $\begin{array}{c}\text { Cambi } \\
(1999 / 1999)\end{array}$ & $\begin{array}{c}14(521 ; 534- \\
6 ; 546-55)\end{array}$ & 702 & 1,99 & $\begin{array}{l}\text { O século XX até os anos 50. "Escolas } \\
\text { Novas" e ideologias da educação. } \\
\text { Renovação da escola e pedagogía } \\
\text { ativista. Novas teorias pedagógicas: o } \\
\text { idealismo. Entre pragmatismo e } \\
\text { instrumentalismo: a pedagogia de } \\
\text { John Dewey. }\end{array}$ \\
\hline $\begin{array}{l}\text { Gauthier \& } \\
\text { Tardif } \\
(2010 / 2010)\end{array}$ & $\begin{array}{c}7(195 ; 197 ; \\
277-8 ; 286 ; \\
323 ; 344)\end{array}$ & 527 & 1,32 & $\begin{array}{l}\text { Pedagogias e pedagogos do século } \\
\text { XX. Da pedagogia tradicional à } \\
\text { pedagogia nova. [...] Carl Rogers e a } \\
\text { pedagogía aberta. A pedagogia de } \\
\text { Paulo Freire ou quando a educação se } \\
\text { torna um ato político. As tecnologias } \\
\text { da informação e da comunicação na } \\
\text { pedagogia. }\end{array}$ \\
\hline
\end{tabular}

Fonte: Elaborado pelos autores.

Com base na análise de conteúdo programático, desenvolver-se-á nos próximos subtópicos uma descrição pormenorizada das ocorrências textuais e discursivas em torno de Dewey nos manuais de História da Educação e/ou Pedagogia mencionados anteriormente.

\subsection{A HISTÓRIA DA EDUCAÇÃO DE PAUL MONROE (1939).}

Paul Monroe (1869-1947) foi Doutor em Filosofia, Professor de História da Educação no Teachers College da Universidade de Columbia (Nova York). Em seu manual História da Educação, publicado pela Companhia Editora Nacional, Paul Monroe não aborda detalhadamente a vida, a obra, o pensamento ou as ações de John Dewey. Todavia, nas Conclusões: A tendência eclética atual, no item $O$ sentido da educação, Paul Monroe assim se refere: 
O professor Dewey define a educação como sendo o processo de reconstrução da experiência enriquecida socialmente pela experiência individual, que dá em troca, ao indivíduo, maior controle de suas próprias forças. Aqui ambos os fatores, individual e social, são acentuados e harmonizados (MONROE, 1978, p. 371).

A razão da ausência de uma leitura mais pormenorizada de Dewey na obra de Monroe é que esta foi publicada em inglês originalmente em 1907 , época em que Dewey ainda não havia atingido seu auge em termos de alcance nas tendências pedagógicas em nível mundial, mas, ainda sim, Monroe tem uma percepção razoável sobre a questão do indivíduo e da sociedade presente em Dewey.

\subsection{A HISTÓRIA DA PEDAGOGIA DE LOUIS RIBOULET (1951)}

Louis Riboulet (1871-1944) foi diplomado em Estudos Superiores de Filosofia e História da Educação, professor no Instituto Notre Dame de Valbenoite, em Saint-Etienne. Nos quatro volumes de sua obra História da Pedagogia, Riboulet não apresenta, sequer de forma pontual, impressões sobre a vida e a obra de Dewey, o que pode ser explicado pelo fato da edição original em francês da obra datar de 1925 .

No quarto volume da História da Pedagogia, publicada pela Editora Coleção FTD, Riboulet dedica algumas páginas a respeito da obra de William James (1842-1910), como um dos representantes da Pedagogia Protestante:

W. James foi professor de psicologia na Universidade de Harvard. Sua filosofia é o pragmatismo e o pluralismo; quer dizer que contém erros consideráveis. O defeito de James é filosofar sobretudo com seu sentimento, sua vontade e seu temperamento. [...] Seria, portanto, perigoso tomar James por guia no domínio das idéias metafísicas. Não é assim em educação; suas teorias são geralmente sãs. Insistiu sobre certo número de idéias importantes e de aplicação constante em educação (RIBOULET, 1951, p. 20). 
Apesar da ressalva em relação às questões metafísicas, Riboulet reconhece o valor das contribuições de William James para a pedagogia contemporânea. Assim, este é o único autor do pragmatismo abordado, nos seguintes tópicos: 1)Respeitar a personalidade do menino; 2) Utilizar os instintos do menino; 3) Compenetrar-se da importância capital da atenção; 4) Favorecer a associação de ideias; 5) Não abusar das lições decoradas; 6) Estabelecer os bons hábitos; 7) Despertar e entreter o interesse.

\subsection{A HISTÓRIA DA EDUCAÇÃO DE ROGER GAL (1954).}

Em sua obra História da Educação, publicada no Brasil pela Editora Martins Fontes, Roger Gal (1906-1966) menciona Dewey apenas na Conclusão, por meio das seguintes considerações:

O homem continua sendo, indiscutivelmente, a realidade em transformação, visto primeiramente aqui e agora, agente, sede e meio de uma inelutável adaptação: escapar aos despotismos da ciência e da técnica; salvar o homem e a natureza. Por isso a pesquisa deve apoiarse nas ciências humanas e sociais, na pediatria, na psicologia, na sociologia etc.; uma "educação nova" nasceu dos eminentes trabalhados de Maria Montessori, Decroly, Dewey, Washburne, Kerschensteiner, Makarenko, Ferrière, Cousinet, Bottrens e Freinet, elucidada pelas pesquisas de Wallon, Piaget, Lewin, Moreno, Rogers. A educação personaliza-se (GAL, 1989, p. 111).

Dessa forma, John Dewey é abordado no contexto dos avanços e dos aprimoramentos dos conhecimentos das ciências naturais, humanas e sociais, sendo então incorporados estes saberes ao processo educacional, originando uma "Educação Nova”. 


\title{
3.4. A HISTÓRIA DA EDUCAÇÃO E DA PEDAGOGIA DE LORENZO LUZURIAGA (1955).
}

O autor espanhol Lorenzo Luzuriaga (1889-1959) menciona de forma bastante pontual a obra e a ação de John Dewey no contexto da "Educação Nova”, quando da abordagem das escolas novas norte-americanas:

\begin{abstract}
A primeira delas foi a famosa "escola primária universitária" (University Elementary School), que Dewey fundou em 1896 como parte da Universidade de Chicago, e onde se propôs experimentar ou comprovar algumas de suas ideias pragmáticas sobre educação. Durou só quatro anos, mas dela surgiram algumas das ideias e métodos característicos da educação norte-americana (LUZURIAGA, 1955, p. 256).
\end{abstract}

Em outras palavras, Luzuriaga destaca a proeminência da "EscolaLaboratório" fundada por John Dewey e sua importância para o desenvolvimento de ideias pedagógicas, influenciando diversos movimentos de renovação em todo o mundo, apesar da efemeridade de sua existência. Por sua vez, em outra ocorrência, Luzuriaga assim descreve: “outro grupo de escolas fundou-se correspondendo mais às ideias das escolas novas europeias de iniciativa privada. [...] Na obra de John e Evelyn Dewey, As Escolas de amanhã, encontram-se exposição e estudo das principais” (LUZURIAGA, 1955, p. 256-7).

A abordagem de Luzuriaga foi centrada no papel das escolas novas, no sentido de se manifestarem como destacado movimento de renovação pedagógica, como alternativa frente à educação tradicional. Por sua vez, relata John Dewey como um dos mais proeminentes educadores que influenciaram as reformas progressistas do ensino nos Estados Unidos, a princípio.

\subsection{A HISTÓRIA DA PEDAGOGIA DE RENÉ HUBERT (1957).}


René Hubert (1885-1954) foi Reitor da Universidade de Estrasburgo (França). O autor dedica nove páginas de sua obra ao pensamento e à ação de John Dewey, no contexto de uma apresentação de algumas das tendências da pedagogia contemporânea (Segunda Parte. As Doutrinas Pedagógicas. Capítulo IV: Algumas tendências da pedagogia contemporânea), juntamente com outros pensadores proeminentes da Contemporaneidade como Durkheim; William James; Kerschensteiner; Giovani Gentili; Alexis Carrel; Aldous Huxley. Para ele,

\begin{abstract}
Na doutrina de John Dewey unem-se o ponto de vista sociológico e o psicológico. Dewey não veio, como James, da fisiologia para a psicologia e para a pedagogia. Manifestou, entretanto, por essa primeira ciência, desde os tempos de estudante, forte interesse; e dele se pôde dizer que foi quem, depois de Huxley, melhor interpretou a doutrina transformista de Darwin no domínio filosófico e nos das práticas sociais, notadamente no tocante à educação. [...] Mas, veio a dedicar-se, sobretudo, após haver sido, um momento, seduzido pelo hegelianismo, aos estudos de psicologia experimental (HUBERT, 1967, p. 312).
\end{abstract}

A seguir, alguns dos pontos destacados por Hubert, sobre John Dewey: 1) relação intrínseca entre a sociologia e a psicologia; 2) educação e vida social em geral; 3) reconciliação entre a teoria e prática (“learning by doing”); 4) Escola-laboratório de Chicago; 5) a questão do método.

A respeito do avanço do conhecimento científico, com base nas ideias de John Dewey, Hubert define que "[...] numa sociedade que funda o progresso humano no desenvolvimento das ciências e das técnicas, tanto valor tem a educação naturalista e científica, quanto a humanista" (HUBERT, 1967, p. 3189). Em outros dizeres, a Educação Nova procura considerar todos os avanços científicos percebidos na contemporaneidade, independentemente da área de atuação, no âmbito do desenvolvimento da escolarização conformada à Ciência, às Artes e às Humanidades. 


\subsection{A HISTÓRIA DA EDUCAÇÃO MODERNA DE FREDERICK EBY (1962).}

Frederick Eby (1874-1968) foi professor de História e Filosofia da Educação na Universidade de Texas. Eby reservou um capítulo (XXIV) para expressar detalhes sobre a obra e a ação de John Dewey, cujo título é: " $O$ Instrumentalismo de John Dewey”. No referido capítulo, Eby desenvolve os seguintes tópicos: o filósofo da América; vida e obra (John Dewey); a Escola Elementar da Universidade; princípios filosóficos fundamentais; obra: "Como pensamos"; a Filosofia da Educação de Dewey. Em relação ao papel e à atuação de John Dewey, Eby (1962) assim estabelece seu posicionamento:

Durante 50 anos, o Dr. Dewey foi o primeiro pensador educacional da América. É considerado por muitos o maior pensador filosófico que o Novo Mundo produziu. Nenhum outro filósofo dedicou tanta atenção ao estudo de problemas educacionais, nem qualquer outro exerceu uma influência tão profunda nas escolas, não só da América no Norte, como também de outros países (EBY, 1962, p. 531).

Em outras palavras, Eby reconhece a proeminência e a atuação de John Dewey como pensador de relevância no contexto do século XX, com ampla influência no movimento progressista e de renovação das questões educacionais nos Estados Unidos e em outros países do mundo todo. Dentre outras questões filosóficas voltadas para o desenvolvimento do conjunto da obra deweyana, Eby (1962) destaca a identificação da educação como um processo social por natureza e não como produto em si. Neste sentido, compreende a relevância do processo educacional para o desenvolvimento social e a conquista civilizatória. Sendo assim,

A educação não é, de modo algum, uma questão trivial que pode ser relegada a mulheres idosas e amas. É um processo social indispensável, um meio para a continuidade e progresso ordenados da sociedade humana. Toda a educação deve realizar-se pela participação do indivíduo nas atividades e nos objetivos da sociedade. É um 
processo pelo qual a civilização é preservada e levada avante em suas tentativas de se completar. A educação é, por conseguinte, a mais fecunda de todas as atividades da sociedade (EBY, 1962, p. 536).

Para Eby, a educação na visão de Dewey é compreendida como um processo de reconstituição da experiência, concedendo-lhe uma perspectiva mais socializante, a partir de um avanço e de um desenvolvimento individual. Educação e experiência são processos intimamente ligados e interdependentes, pois todo o processo de crescimento, desenvolvimento e revisão da experiência coincide com o sentido de educação.

Ainda para Eby, Dewey defende que não há sentido em estabelecermos objetivos ou fins para a educação, pois a questão posta diante dos indivíduos, independentemente de idade ou condição, é o aqui e o agora, ou seja, a educação se constrói continuamente a partir da experiência vivida no tempo e no espaço. A educação ocorre sob a influência de fatores básicos - o individual e o social - na perspectiva de que a sociedade pode ser compreendida como a união orgânica de indivíduos. Por fim, Eby (1962, p. 545) expressa uma crítica ao pensamento de Dewey:

Dewey reivindicava que sua teoria de pragmatismo ou instrumentalismo era uma revolução copernicana na teoria educacional. A analogia não foi, entretanto, feliz. A aceitação da teoria heliocêntrica foi seguida por uma era de unanimidade, paz e incomparável progresso na Astronomia. Justamente o oposto é verdadeiro na educação: confusão, insatisfação e evidente desconfiança têm sido as principais características da educação norteamericana durante meio século. A oposição a muitos dos princípios fundamentais de Dewey assumiu um caráter febril. Em anos posteriores, ele modificou muitas de suas concepções iniciais, em vista das críticas.

\subsection{EDUCAÇÃO E LUTA DE CLASSES DE ANÍBAL PONCE (1963).}


Aníbal Ponce nasceu em Buenos Aires (Argentina), em o6 de junho de 1898 e morreu na Cidade do México, em 18 de maio de 1938. Partindo de uma mentalidade de características liberais, positivistas e pré-socialistas, o autor passa, a partir de 1930, a militar o socialismo (de vertente voltada para o materialismo dialético).

Em sua obra, Educação e Luta de Classes, Aníbal Ponce não aborda a ação e o pensamento de John Dewey, especificamente, o que, provavelmente, pode ser explicado pelo conhecimento precário das ideias de Dewey, dado que a obra de Ponce foi publicada originalmente em 1937.

No Prefácio da edição brasileira do livro, escrito por José Severo de Camargo Pereira, há ponderações no sentido de explicar que o presente autor considera a educação como fenômeno social componente da superestrutura e, dessa forma, parte do princípio de que os fenômenos educacionais somente podem ser entendidos quando expostos em comum com uma análise socioeconômica.

\subsection{A HISTÓRIA GERAL DA PEDAGOGIA DE FRANCISCO LARROYO (1970).}

Francisco Larroyo (1912-1981) é um autor mexicano. No Tomo II de sua História Geral da Pedagogia, há três páginas sobre Dewey (John Dewey e o "ensino pela ação"), nas quais é considerado o contexto da Pedagogia Contemporânea, assim como a aclamada "Pedagogia da Ação", a partir do tópico: "os grandes teóricos da Pedagogia Ativa”:

O teórico genial do novo conceito pragmático da educação foi John Dewey. Foi o primeiro que, com profunda visão, se opôs à Pedagogia herbartiana da "educação pela instrução", a idéia ativista do "ensino pela ação" (learning by doing), pois só a ação manual e intelectual promove a experiência, e a educação não é outra coisa senão uma contínua reconstrução da experiência (LARROYO, 1970, p. 724-5). 
Segundo Larroyo (1970), no entendimento de John Dewey, a educação é compreendida como contínua reconstrução da experiência, processo oportuno e sine qua non para o aperfeiçoamento social. Por outro lado, o filósofo preconiza que o ensino pela ação deve atender ao interesse produtivo da criança, de modo a preservar a questão do progresso social, da coletividade.

\begin{abstract}
Deste elevado ponto de vista, Dewey atribuiu à sua doutrina um vigoroso caráter psicogenético. A educação deve partir dos poderes ou instintos da criança e avançar apoiando-se nos interesses e atitudes do educando, sempre em evolução. Se o ensino não se adapta ao desenvolvimento da criança e do jovem, redundará numa desintegração e perda inútil de energia. Procedendo assim, a velha oposição entre interesse e esforço se desvanece (LARROYO, 1970, p. 725).
\end{abstract}

Em outras palavras, segundo Larroyo (1970), Dewey compreende a experiência adquirida como instrumental ou forma intensa dedicada à manutenção da vida, com destacado desdobramento político, voltado para o aperfeiçoamento de uma democracia social. Logo, entende-se que "a doutrina de Dewey é uma Pedagogia pragmática, instrumentalista, psicogenética, social e democrática” (LARROYO, 1970, p. 726).

Com isso, pode-se considerar que Larroyo define a Pedagogia de Dewey, considerando seus pressupostos filosóficos envoltos pelo pragmatismo, reforçado pelo viés instrumentalista a partir de uma concepção originariamente psicológica, com forte tendência social e democrática.

\title{
3.9. A HISTÓRIA DA PEDAGOGIA, SEGUNDO VOLUME DO TRATADO DAS CIÊNCIAS PEDAGÓGICAS, ORGANIZADO POR MAURICE DEBESSE E GASTON MIALARET (1974-7).
}

A obra Tratado das Ciências Pedagógicas 2 [História da Pedagogia] 
tem como organizadores Maurice Debesse (1903-1998), Professor de Ciências da Educação na Universidade René Descartes (Paris V) e Gaston Mialaret (19182016), que não dedicaram um espaço específico para a abordagem das ideias de Dewey.

Contudo, há referências esporádicas a Dewey nos seguintes fragmentos: "aliás, é fato que não há grandes sistemas filosóficos no tempo da Renascença. Também não há filósofos da educação, ao modo de J.-J. Rousseau, ou de John Dewey.” (DEBESSE; MIALARET, 1977, p. 201); “[...] após Dewey, o Prof. Donald E. Super, da Universidade de Colúmbia, de Nova York, lhe deu o nome de psicologia dos interesses [...], diríamos nós psicopedagogia dos interesses [...]" (DEBESSE; MIALARET, 1977, p. 476); "Nos Estados Unidos da América, as experiências são diversas. Inspiram-se, geralmente, na Psicologia de Stanley Hall, e na Pedagogia de John Dewey, pragmática e experimental, voluntarista e socializante" (DEBESSE; MIALARET, 1977, p. 520).

Neste sentido, os organizadores reconhecem a relevância da obra de Dewey para a contemporaneidade, das ações enquanto educador e referência no campo institucional e da Pedagogia, enfatizando a questão da influência da filosofia pragmática, embasada nas questões da experiência como condição para o conhecimento, a importância da vontade enquanto dimensão psicológica e o fator social entendido como pressuposto para a educação política.

\subsection{A HISTÓRIA DA EDUCAÇÃO DE MARIO ALIGHIERO MANACORDA (1989).}

O autor italiano Mario Alighiero Manacorda (1914-2013) analisa indiretamente a atuação de Dewey no capítulo "O nosso século na direção ao ano 2000", mais especificamente no tópico "A primeira metade do século" e respectivo subtópico "Os problemas da instrução nas democracias burguesas". Por sua vez, trata do pensamento e da atuação de John Dewey no tópico "A segunda metade do século" e no subtópico "Novas tendências dos marxistas e 
dos católicos”.

Manacorda (2004) dedica oito páginas de sua obra para a abordagem do pensamento de Dewey, englobando questões voltadas para a pedagogia, o engajamento educacional e o pensamento filosófico, reconhecendo sua singularidade e desdobramentos na contemporaneidade. Com este intuito, Manacorda assevera: "eu me refiro, antes de tudo, a um pensador americano, John Dewey, máximo teórico da escola ativa e progressista, do learning by doing" (2004, p. 317).

Por sua vez, Manacorda (2004) também demonstra que, na obra de Dewey, a vida escolar e a vida social se confundem, pois, a educação é prerrogativa para o desenvolvimento social, a partir dos sujeitos, em uma perspectiva que, nesse sentido, aproxima-se da visão socialista marxista. Em outras palavras, a escola se configura como um dos instrumentos necessários para o aprofundamento da justiça social.

Em uma (re)visão histórica da educação, segundo Manacorda (2004), Dewey identifica a instrução tradicional do velho mundo como a "escola como mosteiro", em que prevalece o ensino de três habilidades basicamente: ler; escrever e contar. Em seguida, com o avanço da tecnologia industrial em diversos países do mundo, a partir da modernidade, Dewey identifica um novo modelo educacional: "instrução de oficina", inicialmente, avançando em seguida para o "laboratório". Ao tentar estabelecer um posicionamento crítico sobre a obra de John Dewey, Manacorda (2004) assim expressa:

Não é fácil resumir aqui o pensamento e as múltiplas indicações metodológicas da pedagogia de Dewey; é preciso, porém, reconhecer que raramente um pensador mostrou uma tal coerência entre as premissas teóricas e as opções práticas. É mais interessante procurar captar algumas conclusões da sua reflexão, que mostram, ao mesmo tempo, uma progressiva mudança das relações de produção e das forças produtivas nos Estados Unidos e um aprofundamento de suas capacidades críticas (2004, p. 319). 
Manacorda considera John Dewey como uma das referências mais marcantes em termos de pensadores que vislumbram a íntima relação entre produção, trabalho e educação, entre sociedade, política e escola.

Neste sentido, a educação escolar é assumida como instância fundamental para o aperfeiçoamento social, em todas as dimensões, desde a organização cotidiana até a convivência grupal, entendida também como potencial instituição responsável pela preparação diante do exercício da cidadania.

\subsection{A HISTÓRIA DA PEDAGOGIA DE FRANCO CAMBI (1999).}

Franco Cambi (1947-...) é também um autor italiano, atuante na Universidade de Florença. Em relação ao pensamento e à obra de John Dewey, por meio de quatorze páginas, o autor estabelece uma análise no âmbito das "Escolas Novas", enquanto iniciativa de renovação da escola e afirmação da pedagogia ativista, de tendência idealista (hegeliana). Sobre o alcance do pensamento, da obra e das ações de John Dewey, assim estabelece:

Dewey foi o maior pedagogo do século XX: o teórico mais orgânico de um novo modelo de pedagogia, nutrido pelas diversas ciências da educação; o experimentalista mais crítico da educação nova, que delineou inclusive suas insuficiências e desvios; o intelectual mais sensível ao papel político da pedagogia e da educação, vistas como chaves mestras de uma sociedade democrática. Além disso, o pensamento pedagógico de Dewey difundiu-se no mundo inteiro e operou em toda parte uma profunda transformação, alimentando debates e experimentações e a reposição da pedagogia no centro do desenvolvimento cultural contemporâneo nos vários países [...]. Mas Dewey, cumpre lembrar, além de um grande pedagogo (teórico e prático) foi também (e antes ainda) um grande filósofo, que desenvolveu a lição do pragmatismo americano rumo a resultados racionalistas-críticos, metodológicos e ético-políticos, conotados no sentido instrumentalista, isto é, ligados a uma ideia de razão aberta, colocada como instrumento na complexa dinâmica da experiência, 
individual e histórica (CAMBI, 1999, p. 546).

Deste modo, além de ser referenciado de forma esporádica em alguns trechos do texto, é reservado o seguinte capítulo para a apreciação do pensamento e da proposta de John Dewey (CAMBI, 1999, p. 546): "Entre pragmatismo e instrumentalismo: a pedagogia de John Dewey". Para Cambi, Dewey é considerado como um dos pensadores mais renomados do século XX, não apenas pelo estabelecimento de uma teoria pedagógica, a partir de pressupostos pragmatistas, mas também pela capacidade de estabelecer sólidos vínculos entre a teoria e a prática, entendendo o pensamento como instrumento para o desenvolvimento do conhecimento, destacadamente o científico, condição para o aperfeiçoamento e consolidação da vida política, de modelo democrático.

Cambi descreve detalhadamente alguns dos aspectos biográficos de Dewey, destacando a dedicação à Filosofia, à Psicologia e à Educação, além de uma enumeração de suas principais obras, mencionando a fundação da EscolaLaboratório, como um dos marcos da atuação e do engajamento na realidade educacional estadunidense.

Por outro lado, explicita a influência do evolucionismo e do hegelianismo sobre John Dewey, ao desenvolver sua filosofia embasada na noção de experiência, como realidade dinâmica e aberta, na qual cabe ao indivíduo o aperfeiçoamento de sua experiência cognitiva, por meio do método científico, perpassando pelas questões da experimentação, da hipótese e da generalização de princípios.

Neste evolucionismo pragmático e instrumentalista de Dewey, um papel central ocupa a reflexão política, que gira em torno do princípio da democracia, vista como a forma mais avançada e mais atual (na sociedade industrial de massa), mas que deve ser constantemente construída (e reconstruída) por uma obra de educação escolar (formando todo cidadão para a democracia, na escola renovada, isto é, organizada como laboratório e destinada a estimular a atividade 
individual), bem como de desenvolvimento da opinião pública, que permite criar aquela "grande comunidade" capaz de autorregular-se pelo controle coletivo da inteligência livremente desenvolvida e promovida ao centro da vida social (CAMBI, 1999, p. 548).

Para Cambi, entende-se que a reflexão política no pensamento deweyano ocupa papel central, uma vez que a democracia é concebida como o princípio e o modelo de sociedade por excelência, apropriado para o contexto atual e o que de mais avançado existe na história. Todavia, não há possibilidade de compreensão da questão política sem lançar-se na abordagem da questão educacional, condição sine qua non para o aperfeiçoamento social. Sumariamente, segundo Cambi (1999), a questão pedagógica em John Dewey pode ser assim categorizada:

1. como inspirada no pragmatismo e, portanto, num permanente contato entre o momento teórico e o prático, de modo tal que o "fazer" do educando se torne o momento central da aprendizagem; 2. como entrelaçada intimamente com as pesquisas das ciências experimentais, às quais a educação deve recorrer para definir corretamente seus próprios problemas, e em particular à psicologia e à sociologia; 3 . Como empenhada em construir uma filosofia da educação que assume um papel muito importante também no campo social e político, enquanto a ela é delegado o desenvolvimento democrático da sociedade e a formação de um cidadão dotada de uma mentalidade moderna, científica e aberta à colaboração (CAMBI, 1999, p. 549).

\subsection{A PEDAGOGIA, DIRIGIDA POR CLERMONT GAUTHIER E MAURICE TARDIF (2010)}

Os organizadores da obra A Pedagogia - Teorias e práticas da Antiguidade aos nossos dias, Clermont Gauthier (Universidade Laval - Quebec, Canadá) e Maurice Tardif (Universidade Laval - Quebec e Universidade de Montreal, Canadá), consideram o pensamento e a ação de Dewey indiretamente, ao tratar das "Pedagogias e pedagogos do Século XX", destacadamente a 
questão da Pedagogia Tradicional X Pedagogia Nova, sem o desenvolvimento de um exame pormenorizado da temática. Assim se expressam: "em 1894, John Dewey é nomeado professor de psicologia e de pedagogia na Universidade de Chicago e funda a sua famosa escola primária ligada à universidade" (GAUTHIER; TARDIF, 2010, p. 194).

Em Dewey, entende-se que a finalidade da educação nova seja a de consolidar as habilidades e os dons da criança, desde seu nascimento: "John Dewey dizia que a criança procura constantemente resolver os problemas que encontra. [...] O famoso learning by doing de Dewey expressa bem essa ideia de que é fazendo atividades (que correspondem às suas necessidades, que a criança evolui e aprende". (GAUTHIER; TARDIF, 2010, p. 194). Em outro momento, há também a abordagem indireta de John Dewey pelos organizadores da obra quando analisam as contribuições de Carl Rogers e sobre as Tecnologias da Informação e Comunicação - TICs na pedagogia.

\section{CONSIDERAÇÕES FINAIS}

John Dewey pode ser designado como um dos pensadores mais influentes e reconhecidos no século XX, exercendo papel referencial em relação às questões filosóficas e pedagógicas, com destacados desdobramentos na Pedagogia, na Epistemologia, na Política, na Psicologia, na Sociologia etc.

Destarte, sua obra e seu engajamento reverberaram em diversos países, com destaque para aqueles da Europa e da América, voltando-se para o avanço da nomeada educação progressista, por meio do movimento escolanovista.

A perspectiva filosófica de Dewey origina-se no âmbito do Pragmatismo, sendo que o mesmo foi revisitado pele filósofo, de modo que o assinala como um Instrumentalismo. Um dos pontos centrais da filosofia deweyana refere-se à ideia de experiência. A partir desta, o homem tem condições de exercer a racionalidade, no sentido de correspondência entre o conhecido e a realidade. 
Em uma tentativa de superar a educação tradicionalista e a visão meramente especulativa da realidade, a proposta de John Dewey pode ser refletida no empoderamento dos indivíduos, por meio do acesso a uma educação que considera o autêntico lugar assumido pelos educandos, sendo passíveis de aprimoramento da liberdade, enquanto situação assumida por indivíduos, tendo em vista o processo de consolidação da democracia.

No que se refere ao conteúdo que diz respeito a Dewey nos manuais de História da Educação e/ou Pedagogia analisados, é visível que a grande maioria dos manuais publicados em seus idiomas originais na primeira metade do século XX, ou em sua proximidade, são lacunares sobre o pensamento de Dewey.

Na maior parte das vezes, os autores dos manuais apresentam Dewey nas conclusões das obras ou em capítulos relacionados a perspectivas da educação, a saber, respectivamente, conforme autores, ano de publicação no Brasil e ano de publicação original: Monroe (1936/1907); Gal (1954/1948); Luzuriaga (1955/1951); Ponce (1963/1937); Larroyo (1970/1944). Todavia, uma exceção importante pode ser vista em Hubert, originalmente de 1949, com publicação em Português em 1957, com obra que dedicou nove páginas às ideias de Dewey.

Por sua vez, nas obras publicadas originalmente na segunda metade do século $\mathrm{XX}, \mathrm{o}$ número de páginas dedicadas à Dewey foi ampliado, destacadamente nos seguintes autores, por ano de publicação no Brasil, com informação sobre o ano da primeira edição no idioma original e número de páginas, a saber: Eby (1962/1952, quinze páginas); Manacorda (1989/1983, oito páginas); Cambi (1999/1995, quatorze páginas); Gauthier \& Tardiff (2010/2005, sete páginas). Todavia, o manual organizado por Debesse \& Mialaret constitui exceção, pois data originalmente de 1971, com publicação em Português entre 1974 e 1977, contando apenas com três páginas em que Dewey aparece.

Em termos de conteúdo, é interessante notar que Hubert (1957) e Cambi (1999) apontam as influências do pensamento de Hegel e do evolucionismo na elaboração das ideias de Dewey, nas quais o meio institucional seria decisivo para o desenvolvimento das potencialidades dos indivíduos. Em direção próxima, 
Monroe (1939) e Eby (1962) destacam a relação entre indivíduo e sociedade presente em Dewey, sendo que Manarcorda (1989), ainda neste caminho, destaca Dewey como interessado em desvendar a relação entre a educação e o desenvolvimento da sociedade industrial nos Estados Unidos. Diferentemente, a ênfase recai na questão da proeminência da Psicologia no entendimento das propostas de uma Educação Nova em: Gal (1954); Luzuriaga (1955); Larroyo (1970); Debesse \& Mialaret (1974-7); Gauthier \& Tardiff (2010).

Diante deste quadro resultante da investigação, percebe-se que os significados e os sentidos do ensino da História da Educação e/ou Pedagogia ganham proeminentes contornos em um contexto de gênese, de expansão e de consolidação das ditas "ciências da educação", na segunda metade do século XIX. Dessa forma, os referidos manuais escolares refletem os desdobramentos de uma presente campanha em torno da identidade epistemológica das ciências humanas (História, Sociologia, Psicologia), em linhas gerais, assim como sua particularização na abordagem do fenômeno educativo.

Esse aperfeiçoamento das ciências humanas, aliadas à visão filosófica, se desdobra na elaboração e na implantação de cursos de formação de professores, como uma das iniciativas de profissionalização docente, os quais seriam responsáveis pela condução do ensino primário, a partir das demandas sociais em torno da crescente industrialização em países europeus e nos Estados Unidos.

Desta maneira, por exemplo, a abordagem de autores renomados no meio acadêmico, como John Dewey, seja por meio da análise das respectivas matrizes conceituais ou inovações metodológicas, ou através da forma como seu pensamento, obras e práticas são contempladas em manuais escolares, refletem o interesse em avançar a complexidade dos currículos dos cursos de formação de formação de professores. Com isso, nota-se a incorporação de disciplinas como aquelas voltadas para os fundamentos da educação: Filosofia da Educação; Sociologia da Educação; História da Educação; Psicologia da Educação etc.

Os resultados da presente pesquisa demonstram que a abordagem de aspectos teóricos e práticos da atuação de John Dewey, por exemplo, reforçam a 
ideia da necessidade de incorporar junto à formação de professores da primeira metade do século XX, aspectos que lidam com a assimilação da visão radical, de fundamentos, do princípio educativo, como possibilidade de compreensão de suas nuances, ou seja, a formação de professores pressupõe a assimilação de determinadas bases científicas, de modo particularizante, assim como de fundamentos filosóficos, enquanto possibilidade de uma abordagem mais totalizante. Por isso, entende-se que a partir da conciliação entre a teoria e a prática, alcançarmos uma postura emancipada/ emancipadora. Neste caso, por meio de uma formação acadêmica fundamentada em princípios filosóficos e científicos, a atuação de professores na sociedade em geral constituiria condição para a autonomia diante dos desafios educacionais em geral, assim como da prática pedagógica no espaço escolar.

Outro aspecto a considerar é que geralmente, de acordo com as tendências ideológicas ou religiosas dos autores dos manuais em questão, notamos discursos laudatórios e/ou condenatórios em relação aos diversos pensadores da Pedagogia ao longo da História. De todo modo, pensadores como John Dewey gradativamente se tornam referências para os formandos, seja em termos conceituais, teóricos, ou até mesmo quando da implementação de determinados paradigmas metodológicos de ensino, pois os manuais escolares assumem o papel de instrumentos na circulação de ideias, conceitos, paradigmas, metodologias de ensino etc.

Neste caso em específico, por meio dos manuais escolares, John Dewey foi retratado como o principal pensador responsável pelas diretrizes conceituais e práticas do chamado movimento da Escola Nova, incorporando elementos da visão do Idealismo de Hegel (1770-1831), do avanço das ciências, como Biologia, Psicologia e Sociologia. Além disso, Dewey também é citado como o filósofo que incorporou a ideia de que, por meio do desenvolvimento científico e de seu ensino na educação escolar, é possível o desenvolvimento de uma sociedade harmoniosa, fundamentada em princípios colaborativos e democráticos.

Logo, como parte da materialização curricular dos conteúdos prescritos 
pelo desenvolvimento dos saberes científicos e tecnológicos, os manuais escolares são parte destacada das opções escolares em torno da efetivação do ensino no cotidiano escolar, a partir de fins do século XIX e consolidada no decorrer do século XX, contribuindo para a compreensão das nuances históricas em torno do desenvolvimento do ensino, em seus diversos níveis.

Enquanto instrumentos didáticos, os manuais escolares podem fornecer elementos indiciários dos conteúdos escolhidos, dos valores difundidos e das práticas estimuladas na condução da educação, em geral, e da formação de professores, em específico. Com isso, é possível o subsídio de dados informacionais para o aperfeiçoamento dos diferentes saberes que hoje compõem a Pedagogia, assim como para o desenvolvimento de políticas públicas para a educação escolar, geral.

\section{REFERÊNCIAS}

ABBAGNANO, Nicola. Dicionário de Filosofia. Tradução da 1. ed. coordenada e revista por Alfredo Bosi. Revisão da tradução e tradução de novos textos Ivone Castilho Benedetti. 5. ed. (rev. ampl.). São Paulo: Martins Fontes, 2007.

ARAÚJO, José Carlos Souza; RIBEIRO, Betânia de Oliveira Laterza; SOUZA, Sauloéber Társio de. Haveria uma historiografia educacional brasileira expressa pelos manuais didáticos publicados entre 1914 e 1972? In: CARVALHO, Marta Maria Chagas de; GATTI JR., Décio. (org.). O Ensino de História da Educação. Vitória: Edufes, 2011. p. 95-143.

BASTOS, Maria Helena Câmara. Pedagogias e Manuais: Leituras Cruzadas Os Manuais de História da Educação Adotados no Brasil (1870-1950). Mimeo. Pontifícia Universidade Católica do Rio Grande do Sul. 2007.

BASTOS, Maria Helena Câmara. Uma biografia dos Manuais de História da Educação Adotados no Brasil (1860-1950). In: VI Congresso Luso-Brasileiro de História da Educação. Anais... Uberlândia/MG. EDUFU. 2006. p. 334-49. 1 CDROM.

BRANCO, Maria Luísa. O sentido da Educação Democrática: revisitando o 
conceito de experiência educativa em John Dewey. Covilhã: Universidade da Beira Interior, 2011. Disponível em:

<http://www.lusosofia.net/textos/branco_luisa_o_sentido_da_educacao_dem ocratica.pdf $>$ Acesso em: 25 mar. 2016.

CAMBI, Franco. História da Pedagogia. Tradução Álvaro Lorencini. São Paulo, SP: Editora UNESP, 1999.

CHERVEL, André. História das Disciplinas Escolares. Teoria e Educação. Porto Alegre. n. 2, p. 177-229. 1990.

CUNHA, Marcus Vinícius da. John Dewey: uma filosofia para educadores em sala de aula. 2. ed. Petrópolis: Editora Vozes, 1998.

DEBESSE, Maurice; MIALARET, Gaston (org). Tratado das ciências pedagógicas 2 - História da Pedagogia. Tradução Carlos Rizzi, Luiz Damasco Penna e João Batista Damasco Penna. Atualidades Pedagógicas (v. 114). São Paulo, SP: Companhia Editora Nacional, 1977.

DEWEY, John. A Filosofia em Reconstrução. Tradução Eugênio Marcondes Rocha. São Paulo: Companhia Editora Nacional, 1958.

DEWEY, John. Democracia e Educação. Tradução Godofredo Rangel e Anísio Teixeira. São Paulo: Companhia Editora Nacional, 1936.

DEWEY, John. Experiência e Educação. 3. ed.Tradução Anísio Teixeira. São Paulo: Editora Nacional, 1979.

DEWEY, John. Liberalismo, liberdade e cultura. Tradução Anísio Teixeira. São Paulo: Editora Nacional e Editora da USP, 1970.

EBY, Frederick. História da Educação Moderna - Teoria, Organização e Prática educacionais (séc. XVI - séc. XX). Tradução Maria Angela Vinagre de Almeida, Nelly Aleotti Maia e Malvina Cohen Zaide. Rio de Janeiro: Editora. Globo, 1962.

GAL, Roger. História da Educação. Tradução Álvaro Cabral. São Paulo: Martins Fontes, 1989.

GALVÃO, Ana Maria de Oliveira; BATISTA, Antônio Augusto Gomes. Manuais escolares e pesquisa em História. In: VEIGA, Cynthia Greive; FONSECA, Thais Nívia de Lima e (org.). História e Historiografia da Educação no Brasil. Belo Horizonte: Autêntica, 2003.

GATTI JR., Décio. As ideias de Rousseau nos manuais de História da Educação com autores estrangeiros publicados no Brasil (1939-2010). Cadernos de 
História da Educação. Uberlândia/MG, v. 13, n. 2, p. 475-98, jul./dez. 2014.

GATTI JR., Décio. Investigar o Ensino de História da Educação no Brasil: categorias de análise, bibliografia, manuais didáticos e programas de ensino (Séculos XIX e XX). In: GATTI JR., Décio; MONARCHA, Carlos Roberto da Silva; BASTOS, Maria Helena Câmara. (org.). O Ensino de História da Educação em perspectiva internacional. Uberlândia/MG: Edufu, 2009.

GATTI JR., Décio. Percurso histórico e desafios da disciplina História da Educação no Brasil. In: GATTI JR., Décio; PINTASSILGO, Joaquim António de Sousa. (org.). Percursos e Desafios da Pesquisa e do Ensino de História da Educação. Uberlândia/MG: Edufu, 2007. p. 99-139.

GAUTHIER, Clermont; TARDIF, Maurice. A Pedagogia - Teorias e práticas da Antiguidade aos nossos dias. Tradução Lucy Magalhães. Petrópolis/RJ: Editora Vozes, 2010.

HUBERT, René. História da Pedagogia. Tradução Luiz Damasco Penna e João Batista Damasco Penna. Atualidades Pedagógicas (v. 66). 2. ed. São Paulo: Companhia Editora Nacional, 1967.

LARROYO, Francisco. História Geral da Pedagogia. Tomo II. Tradução Luiz Aparecido Caruso. São Paulo: Editora Mestre Jou, 1970.

LUZURIAGA, Lorenzo. História da Educação e da Pedagogia. Tradução Luiz Damasco Penna. Biblioteca Pedagógica Brasileira. Atualidades Pedagógicas (v. 59). São Paulo: Companhia Editora Nacional, 1955.

MANACORDA, Mario Alighiero. História da Educação - da Antiguidade aos nossos dias. Tradução Gaetano Lo Monaco. 11. ed. São Paulo: Editora Cortez, 2004.

MARICONDA, Pablo Rubén. Vida e Obra - Dewey (1859-1952). In: DEWEY, John. Várias Obras. Coleção Os Pensadores. São Paulo: Abril Cultural, 1980.

MONROE, Paul. História da Educação. Tradução Idel Becker. Atualidades Pedagógicas (v. 34). São Paulo: Companhia Editora Nacional, 1978.

NUNES, Clarice. Ensino e Historiografia da Educação: problematização de uma hipótese. Revista Brasileira de Educação. Rio de Janeiro. n. 1, p. 67-79, jan./abr. 1996.

PONCE, Anibal. Educação e luta de classes. Tradução José Severo de Camargo Pereira. 16. ed. São Paulo: Editora Cortez, 1998.

POPKEWITZ, Thomas. Reconhecendo diferenças e fabricando a desigualdade: ciências da educação, escolarização e abjeção. In: CATANI, Denice Bárbara; 
GATTI JR., Décio. (orgs.). O que a escola faz? Elementos para a compreensão da vida escolar. Uberlândia/MG: Edufu, 2015, p.317-343.

REALE, Giovanni; ANTISERI, Dario. História da Filosofia: do Romantismo até nossos dias (v. 3). 2. ed., São Paulo: Paulus, 1991.

RIBOULET, Louis. História da Pedagogia. Tradução Justino Mendes. 4 vols. São Paulo: Editora Coleção FTD Ltda, 1951.

SAVIANI, Dermeval. História da História da Educação no Brasil: balanço prévio e necessário. EccoS. São Paulo. 2008. v. 10. n. especial. p. 147-67.

SAVIANI, Dermeval. História das Ideias Pedagógicas no Brasil.

Campinas/SP: Autores Associados, 2007.

WESTBROOK, Robert Brett. John Dewey. Tradução José Eustáquio Romão e Verone Lane Rodrigues. Coleção Educadores. Recife: Fundação Joaquim

Nabuco, Editora Massangana, 2010.

GERALDO GONÇALVES DE LIMA é professor do Instituto Federal de Educação, Ciência e Tecnologia do Triângulo Mineiro (IFTM - Campus Uberaba). Doutor em Educação, com estágio de pós-doutorado concluído, no Programa de PósGraduação em Educação da Faculdade de Educação da Universidade Federal de Uberlândia (UFU).

E-mail: geraldgli@yahoo.com.br

(ib) http://orcid.org/0000-0002-9371-7785

DÉCIO GATTI JR. é Professor Titular de História da Educação da Faculdade de Educação da Universidade Federal de Uberlândia (UFU). Doutor em Educação (História e Filosofia da Educação) pela Pontifícia Universidade Católica de São Paulo (PUC-SP), com estágio de pós-doutorado concluído na Faculdade de Educação da Universidade de São Paulo (USP). Bolsista de Produtividade em Pesquisa do CNPq. Beneficiário do Edital Pesquisador Mineiro da Fapemig.

E-mail: degatti@ufu.br

(i) http://orcid.org/0000-0002-5876-6733 
Revista História da Educação (Online), 2019, v. 23: e93210

DOI: http://dx.doi.org/10.1590/2236-3459/93210
e-ISSN: 2236-3459 http://seer.ufrgs.br/asphe 
Revista História da Educação (Online), 2019, v. 23: e93210

DOI: http://dx.doi.org/10.1590/2236-3459/93210
e-ISSN: 2236-3459 http://seer.ufrgs.br/asphe (c)

Revista História da Educação - RHE

Associação Sul-Rio-Grandense de Pesquisadores em História da Educação - Asphe Artigo de acesso aberto distribuído nos termos de licença Creative Commons. 